\title{
An Examination of Sixth Graders' Self-Determined Motivation and Learning in Physical Education
}

\author{
Haichun Sun 1 , Ang Chen² \\ ${ }^{1}$ University of South Florida, ${ }^{2}$ University of North Carolina at Greensboro
}

\begin{abstract}
Self-determination theory (SDT), when applied in education, emphasizes helping learners internalize extrinsic motivation so as to regulate their learning behavior from an amotivation state to intrinsic motivation. The purpose of this study was to examine the relationship between SDT components and learning in middle school physical education. Sixth grade students $(n=242)$ from 15 randomly selected schools provided data on SDT and their knowledge and skill learning achievement as assessed using a pre- and post-measurement design. Structural equation modeling analyses revealed that extrinsically regulated motivations and intrinsic motivation contributed little to knowledge and skill achievement and amotivation negatively related to knowledge improvement. Given the fact that the data represented learner responses to an activity centered program, the findings imply that when learning objectives are vague, learners may be motivated to participate in classes but their participation may not contribute much to knowledge and skill achievement.
\end{abstract}

Keywords: intrinsic motivation, extrinsic motivation, amotivation, physical education curriculum

A critical factor that often determines success and failure in learning is learner motivation (Pintrich, 2003). Alexander (2005) articulated that the very first step for educators to take is to understand the nature of learner motivation to foster a positive motivation experience for learners. Without this understanding, Alexander (2005) argued, it would be very difficult for educators to engage students in learning to achieve learning goals. In physical education, Chen and Ennis (2004) suggested that without appropriate motivational strategies, it would be difficult for physical education teachers to help learners to learn and eventually develop healthy, physically active lifestyles. With the acknowledgment of profound potential of the self-determination theory (SDT) (Deci \& Ryan, 1985) in education, the purpose of this study, therefore, was to identify relations between learner self-determined motivation and learning in middle school physical education. The study was expected to help us understand students' self-regulated motivation profiles in relation to their learning achievement.

Sun is with the University of South Florida-Physical Education \& Exercise Science, Tampa FL. Chen is with the University of North Carolina at Greensboro-Exercise and Sport Study, Greensboro, NC. 


\section{Self-Determination Theory}

Most motivation research in education has focused on social cognitive theories (Pintrich, 2003). Although such research symbolizes the critical role of social content and social interactions in students' motivation, Pintrich (2003) argued that the internal locus of causality such as need or motives should be viewed as equally important. Pintrich (2003) summarized that SDT integrates both needs and social cognitive constructs that highlight multiple motivational pathways to adaptive outcomes, such as achievement in learning. In recent years, SDT has gained its popularity in research on student motivation in physical education. Among the contemporary motivation theories, SDT is a theoretical approach that offers an insight into the underlying motivations in the learning process (Guay, Rtelle, \& Chanal, 2008). SDT explains human motivation by focusing on the importance of human inner resources for development and behavioral regulation (Ryan \& Deci, 2000a). According to Deci and Ryan (1985, 2000), human innate needs provide a fundamental basis that energizes and directs behaviors in an environment, such as a classroom, a gymnasium, or a playground.

In SDT, human needs refer to "innate psychological nutriments that are essential for ongoing psychological growth, integrity, and well-being" (Deci \& Ryan, 2000, p. 229). Specifically, the needs for competence, autonomy, and relatedness are considered as the cornerstones of human motivation. In SDT, motivation can be understood in three basic types, intrinsic motivation, extrinsic motivation, and amotivation. Intrinsic motivation indicates that individuals engage in an activity for the sake of the activity itself and for the satisfaction inherent in performing the activity competently (Deci \& Ryan, 1985). An intrinsically motivated person engages in an activity to experience interest and enjoyment in the interaction with the activity rather than external pressures or rewards received during or after the interaction. Intrinsic motivation can result in adaptive cognitive, affective, and behavioral outcomes. For example, Ryan and Deci (2000a) concluded that intrinsically motivated students demonstrate better performances, better engagement, higher quality learning behavior, and a lower dropout rate (Ryan \& Deci, 2000a).

In school contexts, however, rarely is the learner motivation completely intrinsic. Often times events that occur in a school may require students to willingly comply with external regulations. For example, students may work on homework not because homework is fun or interesting or enjoyable to them but because they want to receive good grades, or praises from teachers, or to avoid negative academic consequences. The example suggests that the motivation for homework is extrinsically regulated as it is associated with extrinsic contingencies such as receiving rewards or avoiding punishments. This type of motivation is referred to as extrinsic motivation (Ryan \& Deci, 2000b). Extrinsic motivation includes four types of behavioral regulations: external regulation, introjected regulation, identified regulation, and integrated regulation (e.g., Deci \& Ryan, 1985). Among the four types of extrinsic motivation, the least self-determined is external regulation where the individual is motivated by external demands or reward contingencies (Ryan \& Deci, 2000b). External regulation occurs when one is anticipating a certain outcome associated with the required behavior. Introjected regulation refers to partial or suboptimal internalization in which the individual 
does not fully identify with the value of the behavior expected of him/her and is not ready to accept it as his/her own (Deci, Eghrari, Patrick, \& Leone, 1994). But the individual regulates his/her own behavior to comply with the behavioral expectation. In this extrinsic motivation, the individual is motivated because he/she feels having to rather than wanting to (Deci \& Ryan, 1985). A more self-determined form of extrinsic motivation is identified regulation in which motivation is based on recognition and personal identification with the value of the desired behavior (Ryan \& Deci, 2000b). An individual with identified regulation demonstrates more self-determination as he/she has accepted the desired behavior as personally important and has identified the regulation process as personally necessary. The most self-determined type of extrinsic motivation is integrated regulation. Integration refers to optimal internalization resulting in an ideal self-determined extrinsic motivation. It leads externally controlled motivation (having to) to autonomy-based motivation (wanting to) (Deci et al., 1994; William \& Deci, 1996). The extrinsic motivation at the point derives from an integration of the regulated values into congruence with one's value system (Deci \& Ryan, 1985).

There are situations in which individuals are neither intrinsically nor extrinsically motivated. In SDT, the absence of motivation is referred to as amotivation where an individual lacks the intention to act (Ryan \& Deci, 2000a). When an individual is amotivated, he/she either does not take part in the activity at all or just goes through the motion without intent (Deci \& Ryan, 2000). Research in physical education has revealed that amotivation leads to maladaptive consequences, such as boredom (Ntoumanis, 2001) or lack of intention to participate in after-school physical activities (Standage et al., 2003).

\section{Self-Determined Motivation in Physical Education}

One central hypothesis in SDT is that students who are motivated intrinsically or with identified regulation will have positive and constructive experiences at school more likely than those who are merely motivated by external and/or introjected regulations (Guay et al., 2008). Research in physical education has shown that intrinsic motivation positively predicted students' effort (Ntoumanis, 2001), concentration level (Ntoumanis, 2005; Standage et al., 2005), preference to attempt challenging tasks, positive affect (i.e., happy, satisfied, excited, and relaxed) (Standage et al., 2005), and intension of being physically active after school (Ntoumanis, 2001, 2005; Standage et al., 2003). In addition, students' intrinsic motivation in physical education had significant effects on their choice decisions for participation in optional physical education (Ntoumanis, 2005).

Despite the theoretical hypotheses that external regulation would lead to maladaptive affective or undesirable cognitive consequences, it is still not clear to what extent the external regulation is related to learning achievement, effort in class, intention for after school physical activity (Ntoumanis, 2001), concentration level, and preferences for challenging tasks in physical education (Standage et al., 2005). Due to the fact that very few studies have directly examined the identified regulation in physical education, it is not clear what role of identified regulation plays in the learning process. Although it was found that the introjected regulation did not predict any motivational, affective, or behavioral outcome (e.g., 
Ntoumanis, 2001; Standage et al., 2003, Standage et al., 2005), the role it plays in hindering or contributing to learning achievement in physical education remains unclear.

Learning achievement in physical education can be defined as a relatively permanent behavioral and cognitive changes resulting from experiencing physical movement (Rink, 2001). Learning achievement in physical education, similar to that in other school content areas, can be assessed and documented using cognitive and skill tests (Rink, 2005). These achievement indicators, along with in-class physical activity (physiological intensity), can reflect the outcome of their study in physical education (Chen \& Ennis, 2004). In the current study, learning achievement was operationally defined as the degree to which students' knowledge and psychomotor skill grew or improved after instruction.

In this study, we attempted to identify the extent to which each type of motivation in the SDT framework relates to cognitive knowledge growth and motor skill improvement. Figure 1 is a hypothesized model that we used to guide this study. The model describes the relationship between the SDT motivations and learning. We hypothesized that students' intrinsic motivation and identified regulation would positively predict cognitive knowledge growth and motor skill learning, while the introjected regulation would not. In addition, we hypothesized that the external regulation and amotivation would negatively predict knowledge and motor skill learning. We believe that by exploring the SDT motivation variables in relation to actual learning achievement variables, this study will extend our understanding of SDT motivation function and its actual impact on students' learning achievement to inform physical education curriculum reform. We also hope that the results will provide useful information about this important relationship specific enough that will guide effective development of learning-enhancing motivation strategies in physical education.

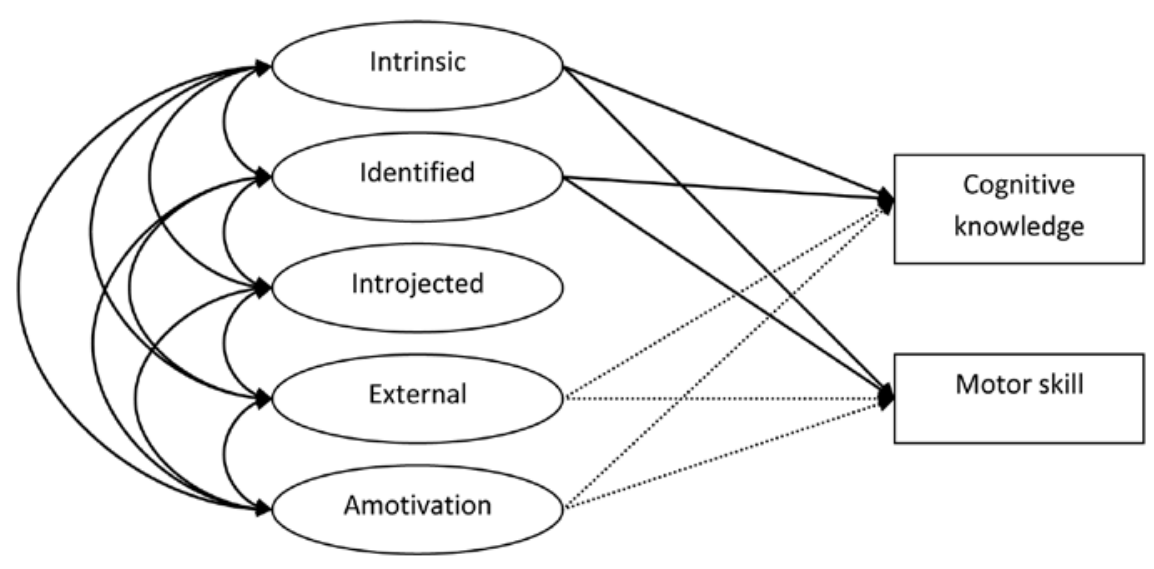

Figure 1. The hypothesized model. Note: Solid lines indicate positive relationships; broken lines represent negative relationships. 


\section{Method}

\section{Setting and Participants}

The study was conducted in a large school district on the East Coast of the United States. The district was representative of the 100 largest school systems in the country within one standard deviation between the means of key system variables such as student-teacher ratio, school finance, enrollment, standard test scores, and socioeconomic status (FARM\% - percentage of students on the federal Free and Reduced Meal program) (National Center for Education Statistics, 2004). The school district offered 180 minutes of physical education per week to middle school students. The students were required to take physical education in three of the four academic quarters throughout the year. All middle schools were equipped with at least one large gymnasium and adequate outside field space for current curriculum offerings. The curriculum focused on educating students to become skillful, fit, and personally and socially responsible movers. The curriculum was the typical multiactivity physical education that exposed students to a variety of sport and physical activities (such as basketball, soccer, dance, archery, badminton, educational gymnastics) for skill and fitness development. Systematic observation data indicated that students in general spent $13 \%$ of class time on management tasks, $9 \%$ on warm up/cool down, $7 \%$ on listening to teacher instruction, $3 \%$ on cognitive tasks, $14 \%$ on fitness activities, $24 \%$ on skill practice, $25 \%$ on games, and $6 \%$ off-task (Chen \& Sun, 2008). Teachers mostly provided positive feedback to motivate students in their physical education classes. Fitness test, cognitive knowledge test, and skill test were routinely administered by physical education teachers in this school district.

Two randomizations were conducted in sample selection. From a pool of 38 middle schools, 15 were randomly selected with stratifications on students' socioeconomic background and school size. Within the schools 344 sixth graders were randomly selected to provide the data for this study. Due to absences, the final sample consisted of 242 students who provided complete data sets. A preliminary analysis indicated that the attrition was not systematic across school, gender, ethnicity, and learning performance, thus can be considered random. The participants represented the following major ethnic groups, 22\% African American, 44.8\% European American, 18.2\% Hispanic American, 18.2\% Asian American, and $0.3 \%$ Native American. All participants in the study had their parent/guardian permission for participation as required by the institution review board regulations. In addition, students were told that they could choose to withdraw whenever they decided to without any consequences.

The sixth grade students were chosen because of the uniqueness of this grade level. Students were in the transition from elementary to middle school during this period of time. At this stage they were experiencing a physical education curriculum different from what they had in elementary school. Therefore, the knowledge and skill growth measured in the study can be largely attributed to the middle school curriculum. In other words, the internal validity for the measure of learning outcome might be better preserved. 


\section{Variables and Measures}

Self-Regulated Motivation. Self-regulated motivations were measured with a questionnaire adapted by Goudas, Biddle, and Fox (1994) based on the original Self-Regulation Questionnaire (SRQ) designed by Ryan and Connell (1989). The modified SRQ has shown distinct factor structures for the SDT components and good internal reliability (Cronbach a ranging from .60 to .80). The SRQ includes five four-item subscales that measure intrinsic motivation, identified regulation, introjected regulation, external regulation, and amotivation. The items are attached to a 7-point Likert type scales with Strongly Disagree as 1 and Strongly Agree as 7. Each item begins with a common stem "I take part in PE..." followed by the statement for rating such as "because physical education is exciting" (intrinsic motivation), "because I want to learn sport skills" (identified regulation), "because I would feel bad about myself if I did not" (introjected regulation), "because I will get into trouble if I don't " (external regulation), and "but I really feel I am wasting my time in physical education" (amotivation). Integrated regulation was not examined in this study. Ryan and Connell (1989) conducted one-on-one interview with children in identifying the structural characteristics of the regulatory reasons they relied on for academic achievement motivation. The researchers reported (1989) that the children were only able to identify the external, introjected, and identified reasons as internalized source of motivation. It is suggested that (The Self-Regulation Questionnaires, n.d.) elementary and middle school students are too young to achieve a sense of integration with respect to school academic activities. Confirmatory factor analysis was conducted to test the tenability of the five-factor SDT model in this study. The indices from the Goodness-of-Fit tests showed that the model fit well with the students' responses: the CFI is .952, RMSEA is .042, and SRMR is .066. The construct reliability coefficient (r) of the measurement model was .875 and all factor loadings were statistically significant, indicating that the hypothesized construct was very stable and replicable.

Cognitive Knowledge Test. Students' knowledge about physical activity and its benefits was assessed using a standardized knowledge test with questions initially developed, validated, and standardized by Zhu, Safrit, and Cohen (1999). The content validity of selected questions was determined using question-by-question deliberations by a group of experienced physical education teachers $(n=6)$. Because scientific content validity had been determined by Zhu et al. (1999), the content deliberations were focused on the age/grade appropriateness of content and wording/vocabularies to be used in the test construction. A 100\% agreement was set as the standard for acceptance of each question. The process generated 37 questions for the sixth grade. A known-group method (Morrow, Jackson, Disch, \& Mood, 2005) was used to further generate validity evidence for each question one year before this study with a random sixth grade student sample of similar size ( $n$ $=287$ ). After receiving the instruction on physical activity benefits and exercise principles the students were given the experimental knowledge tests. Students whose total scores were in the top 27\% were assigned in a "learned" group. Those whose total scores were in the bottom $27 \%$ were classified as "not-learned" group. The index of difficulty and the index of discrimination were computed by contrasting the responses to each question by the two groups of students. The selection of questions was based on typically recommended standards (Morrow et al., 2005) as 
follows: questions with an index of difficulty between $40-60 \%$ were determined as "usable;" those between $45 \%$ and $55 \%$ as "must-use;" those out of these ranges were determined "un-usable." A $40 \%$ threshold was set for the index of discrimination. Those between $40 \%$ - $60 \%$ were classified as "usable;" above $60 \%$ as "must use;" those below $40 \%$ as "un-usable. A total of 24 questions met both standards and were split into two 12-question equivalent tests. The questions were in the multiplechoice format. A correct answer was assigned a score of one; incorrect choice was assigned a score of zero. The maximum possible score a student may earn is 12 . The total score represents the performance on the test and, consequently, represents how much a student knows about the content. The content on the tests was taught during the spring semester when this study was occurred.

Motor Skill Tests. We used a basketball control dribble test and a badminton overhand clear skill test to assess motor skill achievement. It is important to understand that we did not attempt to measure a specific sport skill. Instead, our purpose was to assess psychomotor skills that can be used in a variety of physical activities. The badminton overhand clear skill represents a type of arm striking movement that is required in performing many movement forms involving the upper body (Gallahue, 1996). The striking pattern in the test may also be transferred to learning and playing many sports including tennis, racquetball, handball, and volleyball. Therefore, it has broad implication for effective participation in physical activity. It is also important to notice that basketball and badminton were included in the physical education curriculum and were taught during the spring semester.

The test designed by Lockhart and McPherson (1949) was used in the study due to its standardized nature and accompanying validated norm for scoring. The test-retest reliability coefficient of this test has been reported to be .90 and the concurrent validity coefficient has been reported to range from .71 to .90 by using criterion measures of experts' ratings and round robin tournament (Lockhart \& McPherson, 1949). When taking the test, the student assumed a service stance behind a restriction line $61 / 2$ feet from and parallel to the base of the wall against which the student hit the shuttlecock continuously. A point was scored each time the shuttle was hit during each trial and the total test score was the sum of the legal hits in three trials (See Lockhart \& McPherson, 1994, for detailed description of this test).

The basketball control dribble test (American Alliance for Health, Physical Education, Recreation \& Dance [AAHPRED], 1984) was used to assess students' skill of handling and controlling a basketball while the body is in motion. This test is important in that it emphasizes the skill to coordinate whole body movement, footwork, and object manipulation; all of which are fundamental skills for effective participation in many sports and physical activities. The concurrent validity of the test has been reported to range from .37 to .91 for both genders and the reliability has been showed to range from .93 to .97 for females and from .88 to .95 for males. The test was administered in the regulation-size free-throw lane on the basketball court where the student dribbled the ball around five cones in a zig-zag pattern. The time required to complete the course legally was recorded as the score for a trial. The total test score was the sum of the time for two trials (See AAHPERD, 1984 , for detailed description of the test). 


\section{Data Collection Procedure}

The researchers, participating teachers, and trained data collectors collected data during students' regular physical education classes in the gymnasium. The researchers established the testing protocols and provided series training to physical education teachers and data collectors. This effort was done to minimize the threat to reliability with respect to the discrepancies among the researchers, teachers, and data collectors. In the training sessions, data collection procedures were practiced and the interobserver agreement reliability was conducted and satisfied. In addition, teachers and data collectors received a detailed timeline for administering tests, surveys, and skills to secure the consistency of the protocol across sites. Step-bystep written instructions for administering SRQ and knowledge and skill tests were given to the teachers and data collectors immediately before each data collection session to ensure the protocol was followed faithfully.

Students' knowledge and physical skills were pre- and post-measured to allow growth and improvements to be calculated. The pre-test was conducted in late fall semester, while the post-test was administered in the late spring semester. Knowledge growth and skill improvement scores were obtained by regressing the post-test scores on pre-test scores to control for ceiling effects and any statistically significant discrepancies among groups of students on pre-test scores. Residual gain score was used in the analysis due to the ceiling effect of the raw gain score. For example, students who started with more practice in the skill or concept could be handicapped by the raw gain score. Residual gain score, on the other hand, will control the preexisting difference because it is uncorrelated to the initial performance. Thus, it can be considered as precise and accurate (Williams, Maresh, \& Pebbles, 1972). Students' self-determined motivation was measured in early spring semester.

To secure the independence of students' responses during the data collection, the data collectors instructed students to respond individually and truthfully. Data collectors read items on SRQ and knowledge test to students and answered questions that the students raised. All students were informed that their teachers would not have access to their individual responses and would not use their responses for grading purpose.

\section{Data Analysis}

In addition to descriptive statistics, students' responses to SRQ and their knowledge and skill gain scores were analyzed using the structural equation modeling (SEM). $S E M$ allows the researcher to address theory-driven causal research questions for both latent and the measurement models (Hancock \& Mueller, 2006). In the current study, we used SEM to examine the factor structure of SDT and test the hypothesized relationships between students' self-determined motivation and learning outcomes (Figure 1). In our SEM analysis we first conducted a measurement model specification to examine construct validity evidence from the data by detecting possible discrepancies of the relationships between measurement scores and the latent factors that the scores were meant to represent. In the initial measurement model, all the factors including the stand alone variables were allowed to covary because they theoretically share a certain degree of communalities. When the measurement model specification was successful, we examined the tenability of the structural 
model. At this step, the contribution of each self-regulated motivation to learning achievement was determined using the causal path modeling algorithm to verify if the contributions theorized in Figure 1 were tenable.

\section{Results}

\section{Preliminary Analysis}

The scores from SRQ were reduced according to its requirement for each type of motivation. Knowledge and skill test scores were reduced in terms of the tests' specifications to generate composite scores. Table 1 reports the descriptive statistics for all the measures and Cronbach's alphas for SRQ subscales. As shown, the students reported relatively high intrinsic motivation and identified regulation, moderately low introjected regulation and external regulation), and low amotivation. All subscales had internal reliability coefficients (a) above .70, suggesting that these measures were internally consistent. With respect to skill and knowledge tests, students' badminton skill and health related fitness knowledge scores increased over the semesters. Because the basketball skill test was measured on the time students completed the trial, the higher scores indicated poorer performance (longer time). Therefore, Table 1 demonstrates a slight decline of students' basketball dribble skill from fall 2006 to spring 2007 semester.

We conducted a paired-sample $t$ test and computed the effect size (Cohen's d) on knowledge change and skill improvement to examine learning. Students performed significantly better on knowledge test $(t=-2.391, p=.018$, effect size

Table 1 Means, Standard Deviations, and Cronbach's Alphas for All Subscales

\begin{tabular}{lccc}
\hline & Mean & SD & Alpha \\
\hline Intrinsic motivation & 5.66 & 1.36 & .90 \\
Identified regulation & 5.68 & 1.28 & .83 \\
Introjected regulation & 4.30 & 1.47 & .76 \\
External regulation & 4.14 & 1.64 & .80 \\
Amotivation & 2.53 & 1.54 & .83 \\
Basketball pre-test & 22.91 & 10.41 & \\
Basketball post-test & 23.97 & 7.22 & \\
Residual-gain-score-basketball & -.0244 & 5.36 & \\
Badminton pre-test & 16.26 & 13.65 & \\
Badminton post-test & 23.19 & 16.14 & \\
Residual-gain-score-badminton & .0264 & 13.71 & \\
Knowledge pre-test & 5.56 & 2.02 & \\
Knowledge post-test & 6.08 & 2.56 & \\
Residual-gain-score-knowledge & .0094 & 2.46 & \\
\hline
\end{tabular}


$d=.23$ ) and badminton arm striking skill test ( $t=-6.48, p=.001$, effect size $d=.46$ ) in the post-test than in the pre-test. On the other hand, the decline in basketball control-dribble scores was not statistically significant $(t=1.87, p=.063$, effect size $d=-.12$ ). The values of effect size indicated small deterioration in basketball control-dribble skill, small gain in knowledge learning, and low-moderate gain in the badminton striking skill. Because our research interest was to examine the relationships between students' self-determined motivation and their knowledge gain and skill improvement, the basketball data were eliminated from the final SEM analysis due to the lack of improvement.

\section{Initial Measurement Model Analysis}

The purpose of this analysis was to examine if the data fit initial measurement model so as to allow the further test of the hypothesized structural model. The five SDT factors, cognitive knowledge gain, and motor skill improvement were included in this analysis. Further, the stand alone variables (cognitive knowledge and motor skill) were treated as factors rather than indicators. All factors (SDT constructs, cognitive knowledge, and motor skill) were allowed to covary so that possible discrepant associations could be identified. The robust maximum likelihood method was used in this analysis. The model-data goodness of fit was evaluated by the joint criteria recommend by $\mathrm{Hu}$ and Bentler (1999) where the standardized root mean square residual (SRMR) was used along with one or more incremental or absolute fit indices to determine the fit of the confirmatory factor model. The data-model fit can be considered good when the results meet one of the following two joint criteria: Comparative Fit Index $(\mathrm{CFI}) \geq .95$ and SRMR $\leq .09$; OR SRMR $\leq .09$ and Root Mean Square Error of Approximation (RMSEA) $\leq .06$ (Hu \& Bentler, 1999). The indices from the Goodness-of-Fit tests showed that the initial measurement model fit well with the students' responses: the CFI is .959, RMSEA is .056, SRMR is .062, and Bentler and Bonnett's nonnormed fit index (NNFI) is .949. The construct reliability coefficient ( $\rho$ ) of the measurement model was .899; deemed excellent. In addition, results suggested that all the factor loadings are significant, which further indicates an excellent fit between the theorized factor structure and the data.

\section{Structural Model Analysis}

The hypothesized relationships among the latent motivation constructs and knowledge and skill gains were examined using the maximum likelihood estimation method with EQS6.1 (Bentler, 2006). Goodness-of-fit indexes discussed previously were used to evaluate the model fit. The results of SEM suggested that the hypothesized model fit the data very well. Specifically, with respect to the joint criterion, CFI is .958, SRMR is .062, RMSEA is .039, and NNFI is .949. The construct reliability coefficient is .580 that is considered marginally acceptable (Richman, Mackrides, \& Prince, 1980).

The standardized path coefficients for the hypothesized relationships are presented in Figure 2. As shown, the amotivation negatively related to students' health related fitness knowledge gain. None of the other motivations, including intrinsic motivation, identified regulation, introjected regulation, and external regulation, 


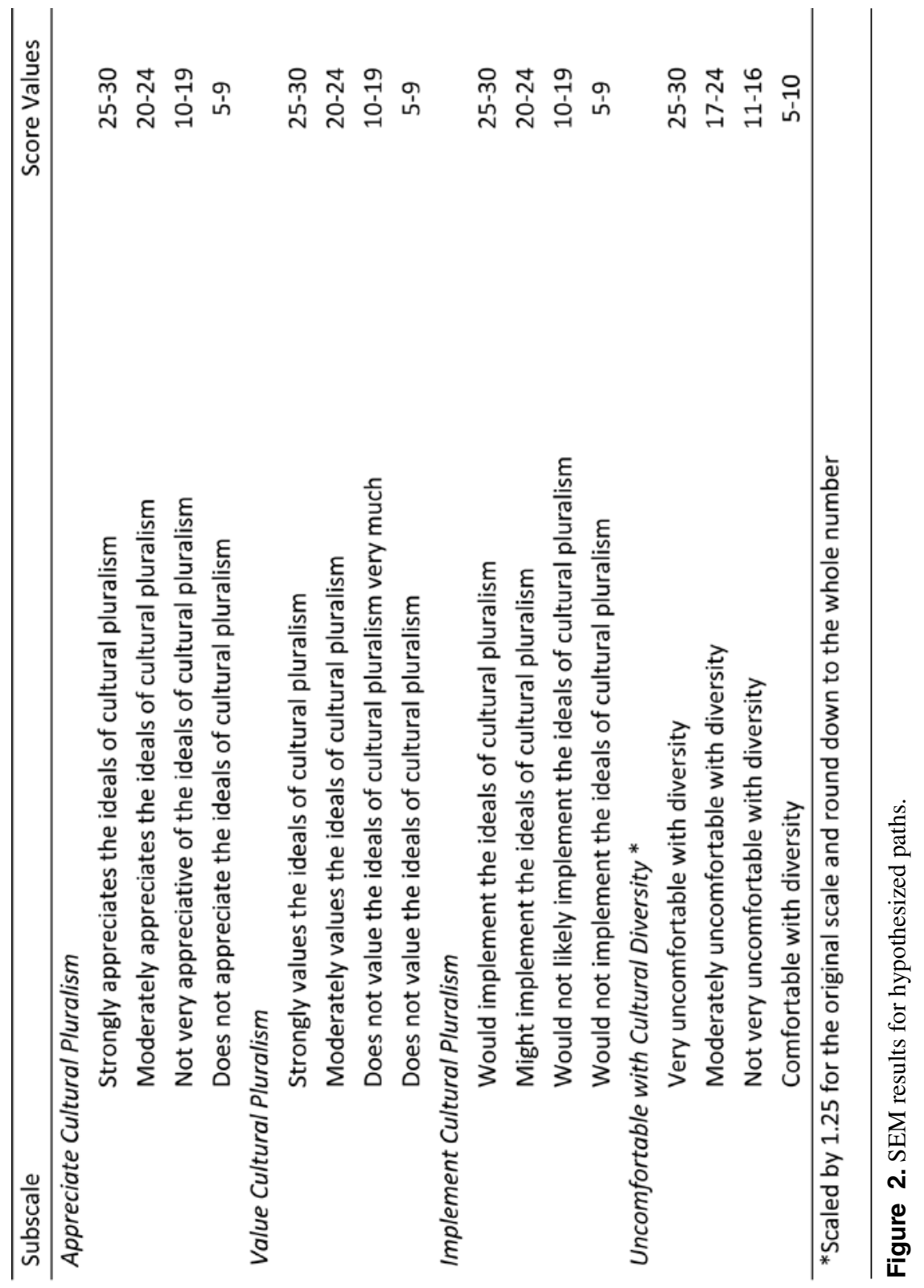


was found relating to knowledge and skill learning achievement, either positively or negatively. Overall, the model accounted for $7.3 \%$ and $3.2 \%$ of the variance in students' knowledge gain and badminton skill improvement.

\section{Discussion}

\section{The Contribution Path of SDT to Learning}

The present study aimed to identify the relationships between students' selfdetermined motivation and learning outcomes in middle school physical education. Results of SEM analysis failed to support our first hypothesized relationship; the link between intrinsic motivation and identified regulation and learning outcomes was not tenable. The results, however, confirmed the negative relationship between amotivation and cognitive knowledge gain. Results suggest that when students lack motivation, they are likely to learn little cognitive knowledge.

In this study, the intrinsic motivation was not related to learning, despite that its positive contribution has been found in other content domains. For example, Deci et al. (1991) found that students who reported high intrinsic motivation were more likely to demonstrate more engagement, lower dropout rate and better academic performance. In physical education, tangible learning achievements as motivational consequences have received little empirical attention in the previous studies. The connection between intrinsic motivation and motivational consequence was only observed in students' cognitive concentration level, such as preference to attempt challenging tasks, and positive affect (i.e., happy, satisfied, excited, and relaxed) (e.g., Standage et al., 2005). A possible explanation for the current findings may be that intrinsic motivation in physical education often derives from and is referred back to fun or enjoyable experiences in activities; and in research it is conceptualized, understood, and measured as such rather than experiences of learning achievement. In instruction, fun is considered a critical task-design priority. When it is overemphasized beyond and steered away from the goal of learning achievement, the fun factor may function as seductive details (Shen, McCaughtry, Martin, \& Dillion, 2006) that suppress the intention to achieve in learning. In other words, we suspect that the physical education content in the participating schools was motivating and engaged the students in class activities. The content, however, might provide "fun" and enjoyable experiences with little emphasis on learning knowledge and skills.

According to SDT (Ryan \& Deci, 2000a), people need to be motivated extrinsically, because not all human activities are intrinsically interesting, optimally challenging, and aesthetically pleasing to everyone. Many activities or tasks in the school and the contemporary society are likely lacking intrinsic motivation characteristics, but they are deemed necessary for students to master. From this perspective, it is critical to understand how extrinsic motivation affects ongoing activities and can be internalized (transformed). At the mean time, it is imperative for educators to explore how nonintrinsically motivated students can be motivated to carry out activities necessary for them in physical education. Our data show, however, the students were extrinsically motivated but their motivation had contributed little to learning in physical education. The results from the descriptive analysis indicate that some students were extrinsically motivated while SEM results showed that all 
three types of extrinsic motivation did not influence student learning. Although it is consistent with our hypothesis that introjected regulation did not contribute to student knowledge and skill learning, it is still a little surprising to see that the identified regulation, a more self-determined motivation, was not found contributing to any learning achievement. External regulation, which was hypothesized to negatively affect student learning, had no relationship with knowledge gain or skill acquisition. Overall, the link between students' extrinsic regulations and their learning in physical education was missing in the current study. This finding may suggest a fact that physical education, if centered on the "busy, happy, good" philosophy (Placek, 1983), can be motivating but the motivation may not lead to effective learning achievement.

\section{SDT Motivation, Learning Achievement, and the Curriculum}

Overall, our descriptive data analysis indicated that students in this study reported relatively high intrinsic motivation and identified regulation and low amotivation. It might be reasonable to assume that physical education can be a motivating subject matter in comparison with general schooling. But experiences in physical education may not necessarily lead to profound learning opportunities. Locke and Lambdin (2003) addressed this issue by asking, "In pursuing our goal of helping children become physically activity for a lifetime... Do we concentrate on helping children to have a wonderful time when moving, or do we focus on helping them acquire skills that will help them enjoy activity in the future?" (p. 76)

What also caught our attention in the findings was that the high motivation did not positively contribute to learning achievement. Motivation is the process that energizes behavior and gives the behavior direction. We found that the sixth grade students were highly motivated in terms of the SDT constructs. However, the motivation did not result in tangible learning achievement. In other words, the students might have motivational energy but lack motivational direction. The issue of lacking motivational direction (achieving learning goals) seems to indicate a need for clearly distinguishing learning goals and nonlearning goals (e.g., having fun) in designing a physical education curriculum (Chen \& Ennis, 2004). The evidence from the current study shows that students were motivated, either extrinsically or intrinsically, in physical education. What needs to be questioned is for what end they devote their motivation? It seems that the students in this study might have not devoted their motivation to learning fitness knowledge and physical skills.

The $t$ tests showed that students' post-test scores of cognitive knowledge and badminton skill were statistically higher than their pre-test scores, suggesting that students did improve their learning. However, caution needs to be taken when we celebrate these achievements. According to the small effect sizes, students' learning of health relatedness fitness knowledge and motor skills might not be as substantial as we educators expected. Moreover, students' basketball control dribble skill decreased over the semesters instead of improving. Despite the fact that students performed significantly better on both the knowledge and badminton tests during the spring semester than they performed in the fall semester, their performances on posttest did not seem to be satisfactory. Given the maximum score on the knowledge test was 12 , students' post-test score $($ mean $=6.08)$ suggested that students' only 
answered half of the questions correctly on average. Similarly, students' badminton post-test performance $($ mean $=23.19)$ indicated that on average students did not master the skill according to the standard (38) of Lockhart-McPherson Badminton Playing Ability Test (Lockhart \& McPherson, 1949). As we discussed above, it seems that their motivation had little to do with the achievement regardless how small it was.

More importantly, the fact that students learned little helps confirm the notion that students in physical education, unlike other school academic areas, have not been held accountable for their learning (Rink, Jones, Kirby, Mitchell, \&Doutis, 2007). More than two decades ago, Goodlad (1984) found that physical education did not appear to have specific learning goals. Siedntop, Doutis, Tsangaridou, Ward, and Rauschenbach (1994) further pointed out that having fun seems to be a dominant goal and students learn little no matter how interested they are in physical education. Although the national effort to develop learning centered curriculum has been made for more than a decade, physical education still has been left without a means to hold teachers and students accountable for learning (Rink et al., 2007).

In summary, the findings of this study revealed a common phenomenon in physical education: the absence of connection between students' motivation and learning. Results showed that students did not lack motivation but they learned little regardless of their motivation. The findings clearly demonstrate a strong need for a learning-oriented, motivating curriculum to help all students learn to become physically educated. Limitations of the study must be recognized. This study is a correctional study; longitudinal and experimental research studies are needed in the future to understand the development of motivations in relation to students' learning in physical education.

\section{Reference}

Alexander, P.A. (2005). Psychology in learning and instruction. Columbus, OH: PrenticeHall.

Bentler, P.M. (2006). EQS structural equations modeling software (Version 6.1). Encio, CA: Multivariate Software. [Computer software].

Chen, A., \& Ennis, C.D. (2004). Goal, interest, and learning in physical education. The Journal of Educational Research, 97, 329-338.

Chen, A., \& Sun, H. (2008). Dissecting contributions: Experiences in elementary and middle school physical education. Sport Pedagogy Research, Policy, and Practice: International Perspectives in Physical Education and Sports Coaching. Proceedings of the AIESEP International Congress, Sapporo, Japan.

Deci, E.L., Eghrari, H., Patrick, B.C., \& Leone, D.R. (1994). Facilitaing internalization: The self-determination theory perspective. Journal of Personality, 62, 119-142.

Deci, E.L., \& Ryan, R.M. (1985). Intrinsic motivation and self-determination in human behavior. New York: Plenum.

Deci, E.L., \& Ryan, R.M. (2000). The "what" and "why" of goal pursuits: Human needs and the self-determination of behavior. Psychological Inquiry, 11, 227-268.

Deci, E.L., Vallerand, R.J., Pelletier, L.G., \& Ryan, R.M. (1991). Motivation in education: The self-determination perspective. Educational Psychologist, 26, 352-346.

Gallahue, D.L. (1996). Developmental physical education for today's children (3rd ed.). Times Mirrior Higher Education Group, Inc. 
Goodlad, J.I. (1984). A place called school: Prospects for the future. New York: McGraw-Hill.

Goudas, M., Biddle, S.J.H., \& Fox, K.R. (1994). Perceived locus of causality, goal orientations, and perceived competence in school physical education classes. The British Journal of Educational Psychology, 64, 453-463.

Guay, F., Ratelle, C. F., \& Chanal, J. (2008). Optimal learning in optimal contexts: The role of self-determination in education. Canadian Psychology, 49, 233-240.

Hancock, G.R., \& Mueller, R.O. (2006). Structural equation modeling: A second course. Greenwich, CT: Information Age Publishing, Inc.

Hu, L., \& Bentler, P.M. (1999). Cutoff criteria fro fit indexes in covariance structure analysis: Conventional criteria versus new alternatives. Structural Equation Modeling, 6, 1-55.

Locke, L.F., \& Lambdin, D. (2003). Putting research to work in elementary physical education. Champaign, IL: Human Kinetics Publishers.

Lockhart, A., \& McPherson, F.A. (1949). The development of a test of badminton playing ability. Research Quarterly, 20, 402-405.

Morrow, J., Jackson, A., Disch, J., \& Mood, D. (2005). Measurement and evaluation in human performance (3rd ed.). Champaign, IL: Human Kinetics.

National Center for Education Statistics. (2004). Characteristics of the 100 largest public elementary and secondary school districts in the United States. Washington, DC: U. $\mathrm{S}$. Department of Education.

Ntoumanis, N. (2001). A self-determination approach to the understanding of motivation in physical education. The British Journal of Educational Psychology, 71, 225-242.

Ntoumanis, N. (2005). A prospective study of participation in optional school physical education using a self-determination theory framework. Journal of Educational Psychology, 97, 444-453.

Pintrich, P.R. (2003). A motivational science perspective on the role of student motivation in learning and teaching contexts. Journal of Educational Psychology, 95, 667-686.

Placek, J.H. (1983). Conceptions of success in teaching: Busy, happy, and good? In T. Templin \& J. Olson (Eds.), Teaching in Physical Education (pp. 46-56). Champaign, IL: Human Kinetics.

Richman, J., Mackrides, L., \& Prince, B. (1980). Research methodology and applied statistics, part 3: Measurement procedures in research. Physiotherapy, 32, 253-257.

Rink, J.E. (2001). Investigating the assumptions of pedagogy. Journal of Teaching in Physical Education, 20, 112-128.

Rink, J.E. (2005). Teaching physical education for learning. Boston, MA: McGraw-Hill.

Rink, J.E., Jones, L., Kirby, K., Mitchell, M., \& Doutis, P. (2007). Teacher perceptions of a physical education statewide assessment program. Research Quarterly for Exercise and Sport, 78, 204-215.

Ryan, R.M., \& Connell, J.P. (1989). Perceived locus of causality and internalization: Examining reasons for acting in two domains. Journal of Personality and Social Psychology, 57, 749-761.

Ryan, R.M., \& Deci, E.L. (2000a). Self-determination theory and the facilitation of intrinsic, social development, and well-being. The American Psychologist, 55(1), 68-78.

Ryan, R.M., \& Deci, E. (2000b). Intrinsic and extrinsic motivation: Classic definitions and new directions. Contemporary Educational Psychology, 25, 54-67.

Shen, B., McCaughtry, N., Martin, J., \& Dillion, S. (2006). Does "sneaky fox" facilitate learning? Examining the effects of seductive details in physical education. Research Quarterly for Exercise and Sport, 77, 598-506.

Siedntop, D., Doutis, P., Tsangaridou, S., Ward, P., \& Rauschenbach, J. (1994). Don't sweat gym! An analysis of curriculum and instruction. Journal of Teaching in Physical Education, 13, 375-394.

Standage, M., Duda, J.L., \& Ntoumanis, N. (2003). A model of contextual motivation in physical education: Using constructs from self-determination and achievement goal 
theories to predict physical activity intentions. Journal of Education \& Psychology, 95, 97-110.

Standage, M., Duda, J.L., \& Ntoumanis, N. (2005). A test of self-determination theory in school physical education. The British Journal of Educational Psychology, 75, 411-433.

The self-regulation questionnaires. (n.d.). Retrieved December 8, 2009, from http://www. psych.rochester.edu/SDT/measures/SRQ_text.php

Williams, G.C., \& Deci, E.L. (1996). Internalization of biopsychosocial values by medical students. Journal of Personality and Social Psychology, 70, 767-779.

Williams, J.D., Maresh, R.T., \& Pebbles, J.D. (1972). A comparison of raw gain scores, residual gain scores, and the analysis of covariance with two modes of teaching reading. Paper presented at the Annual Meeting of the American Educational Research Association, Chicago, Illinois.

Zhu, W., Safrit, M., \& Cohen, A. (1999). Fit Smart: The national health-related physical fitness knowledge test. Champaign, IL: Human Kinetics. 